\title{
Stress path dependent small strain stiffness of Shanghai clay
}

\author{
Xiaoqiang $\mathrm{Gu}^{1,2^{*}}$, Youhong $\mathrm{Li}^{1}$, Fayun Liang ${ }^{1}$ and Maosong Huang ${ }^{1}$ \\ ${ }^{1}$ Department of Geotechnical Engineering \& Key Laboratory of Geotechnical and Underground Engineering of the Ministry of \\ Education, Tongji University, Shanghai, 200092 China \\ ${ }^{2}$ State Key Laboratory for Geomechanics and Deep Underground Engineering, China University of Mining and Technology, Xuzhou, \\ 221116 China
}

\begin{abstract}
The soil small strain stiffness plays an important role in many geotechnical applications such as machine foundations, deep excavations and earthquake ground response analysis. In this study, the small strain stiffness of saturated intact Shanghai clay specimen is measured in a hollow cylinder apparatus. The lateral earth pressure coefficient at rest is measured first during the one-dimensional consolidation. After consolidation, the very small strain stiffness is obtained by shear wave measurement using bender elements, while the degradation of small strain stiffness with strain is investigated by quasi-static loading with high resolution linear variable displacement transducers (LVDT). The effect of stress path on the small strain stiffness is also investigated. The results show that the small strain stiffness is nonlinear and significantly depends on the stress path.
\end{abstract}

\section{Introduction}

The design of many geotechnical projects are controlled by the serviceability (i.e. deformation) rather than stability (i.e. strength) requirement, and therefore the prediction and control of deformation becomes crucial, especially in developed urban area such as Shanghai. Both numerical and experimental studies convincingly indicated that the soil strain level around well-designed structures is typically less than $0.1 \%$ [1]. Therefore, the soil stiffness at small strain level plays a very important role in the deformation analysis of these structures. The small strain stiffness of soil generally consist two parts, including the very small strain stiffness and the nonlinear degradation of stiffness. In the past, many studies have been carried out on the small strain stiffness and it is found that many factors affecting the small strain stiffness, such as soil type, confining pressure, void ratio, fabric, aging, strain history (OCR), stress path, sample disturbance and so on [2-6].

The very small strain shear modulus $G_{0}$ has been extensively investigated in soil dynamic by resonant column or pulse shear wave velocity measurement. In particular, the piezo bender elements for shear wave velocity measurement have been widely implanted in many laboratory apparatus (e.g. triaxial [7], resonant column [8] and oedometer [9]) and now it generally becomes a routine test to determine the $G_{0}$ of the sample. It was found that the $G_{0}$ value of a soil mainly depends on the stress components in the shear-wave plane and the void ratio of sample. Moreover, the shear wave measurements in different planes also indicate that the small strain stiffness is anisotropic due to anisotropic stress state and anisotropic fabric. Li et al. [10] showed that at isotropic stress state the ratio of small strain stiffness in the horizontal plane $G_{0 \mathrm{hh}}$ to that in the vertical plane $G_{0 \mathrm{vh}}$ of the Shanghai clay is around 1.21, indicating the fabric anisotropy.

Regarding the nonlinear behavior of small stain shear stiffness, it is usually represented by the modulus reduction curve which plots the normalized shear modulus $G / G_{0}$ against the shear strain. The modulus reduction curve is usually measured by the resonant column and expressed by a hyperbolic curve. It should be emphasized that the resonant column measure the secant loading-unloading shear modulus subjected to cyclic torsional shear and the stress state is usually isotropic. However, the initial stress state is anisotropic K0 condition in general and the stress path in most project is monotonic. The modulus reduction curve of soil in monotonic loading is usually measured by undrained triaxial test with local strain measurements using liner variable displacement transducer (LVDT) with high resolution [11-12]. The effect of stress path on the modulus reduction curve was also studied. However, the difference of the modulus reduction curves obtained from resonant column and monotonic triaxial tests has not been well studied.

In study, the lateral earth pressure coefficient at rest (i.e. $K_{0}$ ) of typical Shanghai clay is measured by onedimensional consolidation in a GDS hollow cylinder apparatus. The $K_{0}$ consolidated specimen is sheared along different stress paths and the small strain is measured by local LVDT. The modulus reduction curves along different path are determined and compared.

\footnotetext{
* Corresponding author: guxiaoqiang@tongji.edu.cn
} 


\section{Material, procedure and apparatus}

The tests are carried out on intact Shanghai clay samples which are obtained during the site investigation of a deep sewage tunnel constructed in Shanghai. The bottom of the tunnel is around $60 \mathrm{~m}$ below the ground surface and the depth of the diaphragm wall for the shaft is about $110 \mathrm{~m}$. The test samples are collected at around $30 \mathrm{~m}$ and $70 \mathrm{~m}$ below the ground surface. The main physical properties of the sample are listed in Table 1. As seen in Table 1, the physical properties of three specimens at the same depth are nearly the same.

Table 1. The main properties of the tested Shanghai clay.

\begin{tabular}{|c|c|c|c|}
\hline Depth & Density $(\mathrm{g} / \mathrm{cm} 3)$ & $\begin{array}{c}\text { Water content } \\
(\%)\end{array}$ & PI \\
\hline $30 \mathrm{~m}$ & $1.82,1.84,1.86^{*}$ & $37.7,40.3,40.4$ & 15.2 \\
\hline $70 \mathrm{~m}$ & $1.97,2.00,2.02$ & $24.1,25.3,25.5$ & 14.8 \\
\hline
\end{tabular}

A cyclic hollow cylinder apparatus (HCA) is used to perform the tests. The HCA is equipped with high resolution vertical and radial LVDT for small strain measurement as well as bender elements for shear wave measurement. In this study, the specimen is a solid cylinder instead of a hollow cylinder in order to use the bender element. The diameter and the height of the specimen are $70 \mathrm{~mm}$ and $140 \mathrm{~mm}$, respectively. A pair of vertical LVDT is attached on the central $2 / 3$ of the specimen surface, while the radial LVDT is placed at the middle of the specimen, as shown in Fig. 1.

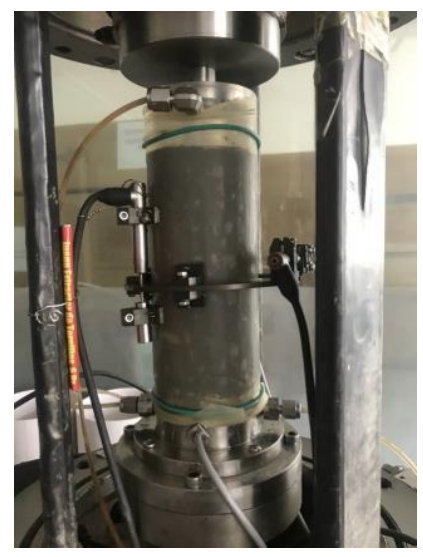

Fig. 1. The arrangement of the local LVTDs on a specimen.

The specimen is saturated by increasing the back pressure until the pore water pressure coefficient $B$ is larger than 0.95 . During the saturation, an effective confining pressure of $10 \mathrm{kPa}$ is applied. After saturation, one-dimensional consolidation is carried out to measure the coefficient of lateral earth pressure at rest $K_{0}$. Then, the specimen is sheared in the undrained condition along the designed stress path. The small axial strain and radial strain are measured by the vertical LVDT and radial LVDT, respectively. Based on the measured stress-strain curve, the equivalent secant Young's modulus and shear modulus can be calculated.

\section{Test results and discussions}

\subsection{The $K_{0}$ of Shanghai clay}

The initial stress state of soil has a significant effect on its behavior. The vertical initial stress can be calculated based on the soil unit weight and soil depth, while the lateral stress is determined by the $K_{0}$ value and the vertical stress. Therefore, the $K_{0}$ value is a very important parameter. During the one-dimensional consolidation, the lateral confining pressure increases to a designed value at a rate of $10 \mathrm{kPa} / \mathrm{h}$ to ensure the fully drained condition. Meanwhile, the vertical stress is servo-controlled based on the strain measurement of radial LVDT to ensure the zero lateral deformation.

Fig. 2 shows the evolution of axial strain and radial strain of a specimen at a depth of $30 \mathrm{~m}$ during the consolidation. As seen in Fig. 2, it is clearly that the radial strain is always zero, indicating that the one-dimensional consolidation is fully satisfied. After consolidation, the axial strain is around $8 \%$. Fig. 3 shows the evolution of $K_{0}$ during the consolidation. The $K_{0}$ value is calculated based on the traditional definition as

$$
K_{0}=\frac{\sigma_{3}^{\prime}}{\sigma_{1}^{\prime}}
$$

where $\sigma_{3}^{\prime}$ is the effective radial stress and $\sigma_{1}^{\prime}$ is the effective vertical stress without lateral deformation, respectively.

As seen in Fig. 3, the initial $K_{0}$ value is 1.0 , which is resulted from the initial isotropic stress state. As the vertical effective stress $\sigma_{1}^{\prime}$ increases, the $K_{0}$ value first decreases and it reaches a steady value when the vertical stress is higher than $100 \mathrm{kPa}$ in general. This steady value is treated as the "true" $K_{0}$ value of the soil. Gu et al. [13] showed that the effect of initial isotropic stress state can be eliminated when the vertical stress is 8-10 times higher than the initial isotropic value and the steady value is very close to the $K_{0}$ value in oedometer. For this specimen, the $K_{0}$ value is determined to be 0.56 . The $K_{0}$ values of the specimen at $70 \mathrm{~m}$ is about 0.49 , which is somewhat smaller than the value of the specimen at $30 \mathrm{~m}$. It is possibly due to the higher density of the specimen at 70 $\mathrm{m}$, which resulted in a higher capacity to resist the external load and therefor a smaller $K_{0}$ value.

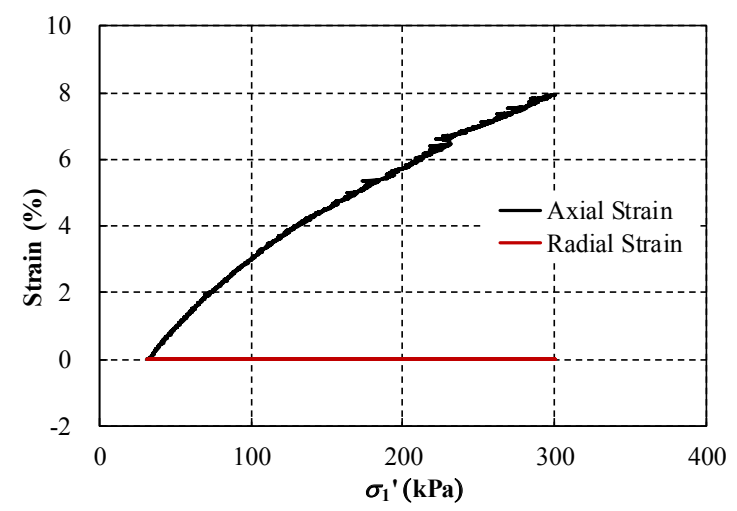

Fig. 2. The axial and radial strains during the $\mathrm{K}_{0}$ consolidation. 


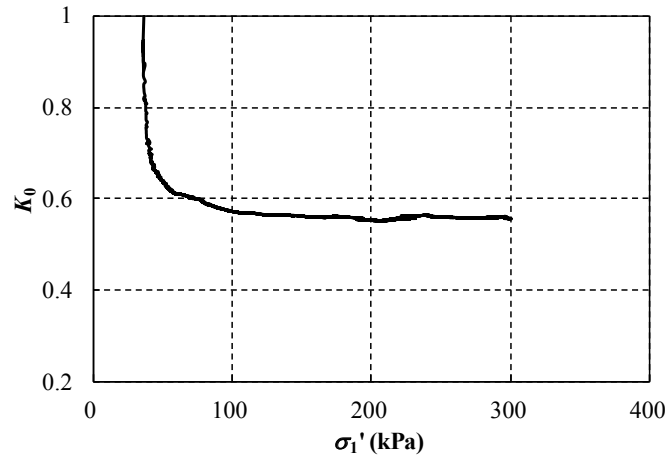

Fig. 3. The evolution of $K_{0}$ during the consolidation.

\subsection{The shear wave velocity of Shanghai clay}

The shear wave of the specimen during the $K_{0}$ consolidation is measured by the bender element mounted in the pedestal and top cap. Figure 4 shows the wave signals for different input frequencies in the specimen after consolidation. As seen in Fig. 4, the received wave signals significantly depends on the input frequency. It is found that the first part of the received signal is the fast Pwave signals, whose velocity is close to the one in water as expected. The amplitude of the P-wave part generally increases as the input frequency increases. The second part of the received signal is the S-wave and its amplitude generally deceases as the input frequency increases. Based on the received wave signal at $10 \mathrm{kHz}$, the shear wave travel time can be determined to be $670 \mu \mathrm{s}$, corresponding to a shear wave velocity $V_{\mathrm{s}}$ of $183.7 \mathrm{~m} / \mathrm{s}$. It is found that the input frequency has a negligible effect on the shear wave velocity here. The details about the signal interpretation for travel time determination in bender element tests can be found in Yang and $\mathrm{Gu}$ [14] and $\mathrm{Gu}$ et al. [15].

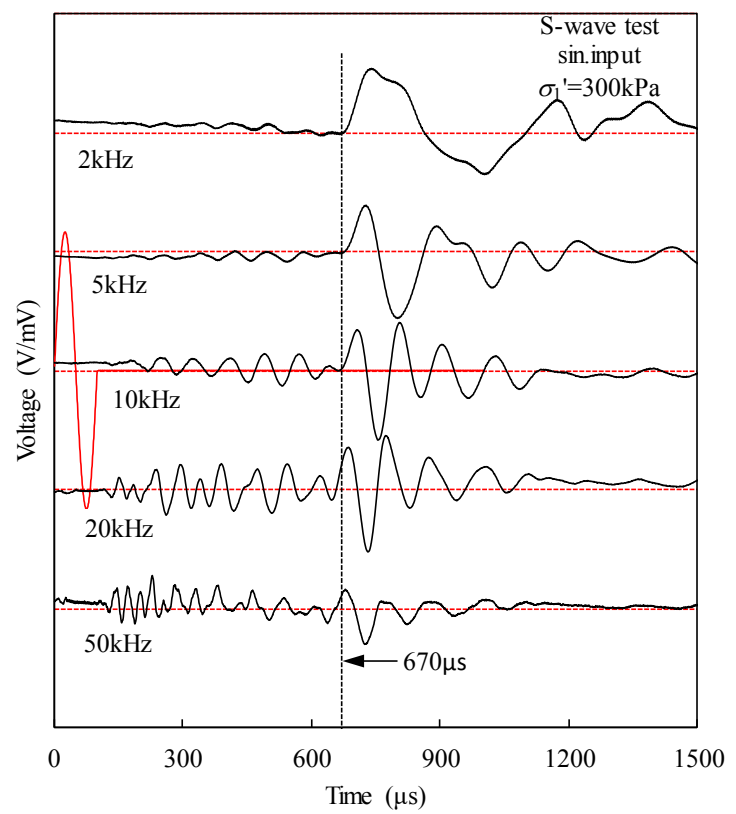

Fig. 4. The received signals in an S-wave bender element test.

Based on the shear wave velocity, the small strain shear modulus $G_{0 \mathrm{vh}}$ can be calculated according to
$G_{o v h}=\rho\left(V_{s}\right)^{2}$, where $\rho$ is the density of the specimen. Figure 5 shows the small strain shear modulus of the 3 specimens during the $K_{0}$ consolidation. As seen in Fig. 5, the $G_{0 \mathrm{vh}}$ values of 3 specimens increase with vertical effective stress as expected, indicating the stressdependent small strain shear stiffness. After $K_{0}$ consolidation, it is found that the small strain stiffness $G_{0 \mathrm{vh}}$ at $30 \mathrm{~m}$ and $70 \mathrm{~m}$ are $64.0 \mathrm{MPa}$ and $192.1 \mathrm{MPa}$, respectively. Meanwhile, the $G_{0 \mathrm{vh}}$ values of three specimens are nearly the same, indicating that the initial stiffness of the specimens for investigating the effect of stress path (see Fig. 6) are approximately identical. It ensures that the observed difference of soil behavior along different stress paths is caused by the stress path, rather than the difference of initial condition of the tested specimens.

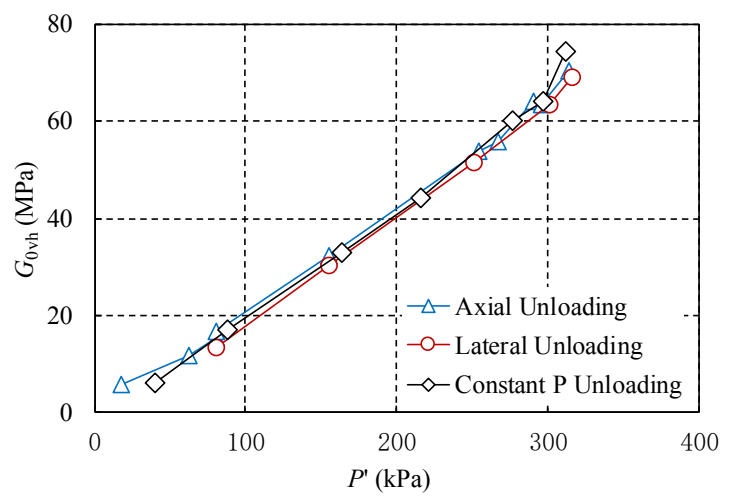

Fig. 5. The evolution of the small strain stiffness of three specimens during consolidation.

\subsection{The effect of stress path}

To investigate the effect of stress path on the small strain stiffness, the specimen is sheared in undrained condition along the typical stress path involved in excavations, as shown in Figure 6. As seen in Fig. 6, three stress paths, including axial unloading, lateral unloading and constant$\mathrm{P}$ unloading, are adopted. The radial and the axial strains are measured by local LVDTs. The axial stress is measured by the internal load cell, while the lateral stress is measured by the GDS pressure controller. During the undrained shearing, the excess pore water pressure is also monitored.

Fig. 7 shows the stress-strain curves and the generation of excess pore water pressure $u$ of the specimens along different stress paths. As seen in Fig. 7, for the lateral unloading path, the deviatoric stress $q=\sigma_{1}^{\prime}$ - $\sigma_{3}^{\prime}$ increases continuously as the axial strain $\varepsilon_{1}$ increases, while it decreases continuously for the stress paths of axial unloading and constant $\mathrm{P}$ unloading $\left(P=\left(\sigma_{1}+2 \sigma_{3}\right) / 3\right)$. The stress strain curves for the axial unloading and constant $\mathrm{P}$ unloading are quite similar. Nevertheless, the generations of excess pore water pressure for different stress paths are quite different. For the constant $\mathrm{P}$ path, the pore water pressure increases first then decreases, while it decreases continuously for the lateral unloading stress path. For the axial unloading, the pore water pressure decreases first and then increases slightly and finally 
decreases. Note that the initial pore water pressure equals the back pressure of $200 \mathrm{kPa}$. Fig. 7 also indicates that the axial strain at failure in triaxial extension mode is smaller than that in triaxial compression mode.

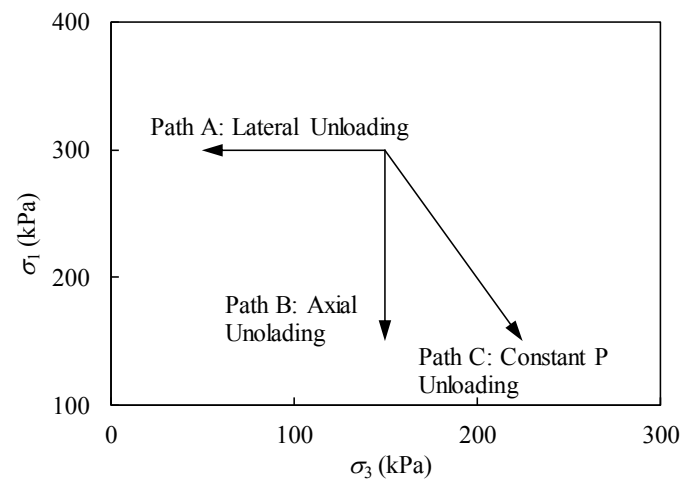

Fig. 6. The stress path used in the monotonic shearing test.

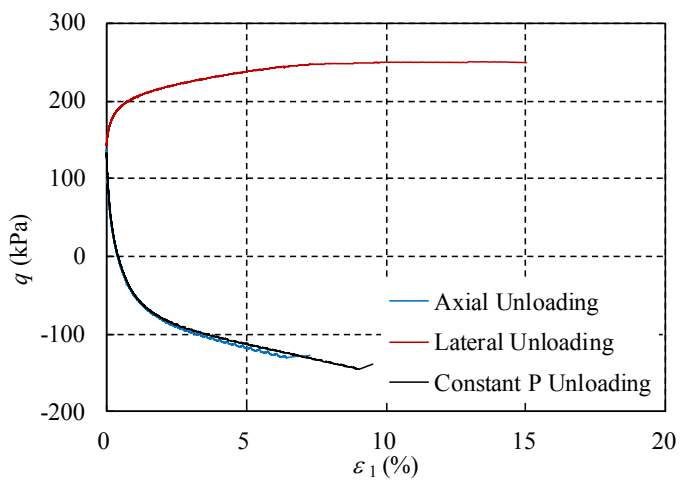

(a)

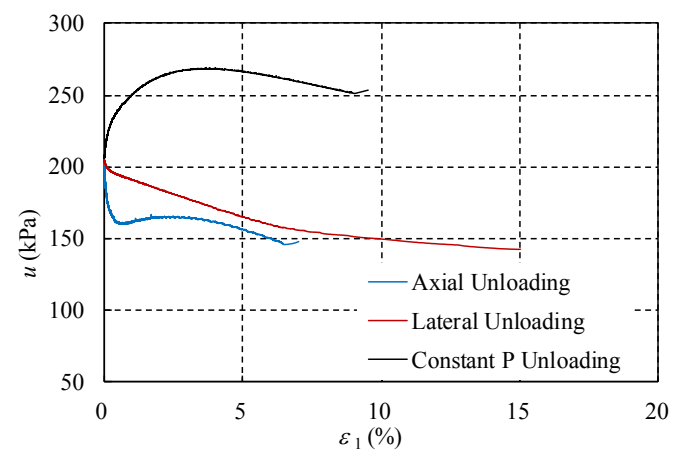

(b)

Fig. 7. (a) The deviatoric stress $q$ and (b) the generation of excess pore water pressure $u$ along different stress paths.

Since the strain level in geotechnical engineering at serviceability state is generally less than $0.1 \%$, it is important to investigate the soil behavior at this small strain range. Fig. 8 compares the stress-strain curves along different stress paths for the axial strain less than $0.1 \%$. As seen in Fig. 8, the stress strain curve for the lateral unloading is much flatter than those for axial unloading and constant $P$ stress paths as expected. The reason is that the deviatoric stress increases along the lateral unloading path which corresponds to a "loading" shear stress path for the soil, but the deviatoric stress decreases along the axial loading and constant $\mathrm{P}$ unloading paths which corresponds to an "unloading" shear stress path. Meanwhile, the stress strain curve along the constant $\mathrm{P}$ path is somewhat flatter than that along the axial unloading, indicating a lower stiffness. These observations are consistent with those in Finno and Kim [12], Hight et al. [16] and Gasparre et al. [17].

For better illustration, the secant Young's modulus $E_{\text {sec }}$ calculated by following Eq. (1) is compared for different stress paths.

$$
E_{\mathrm{sec}}=q / \varepsilon_{1}
$$

Fig. 9 compares the secant Young's modulus $E_{\text {sec }}$ of the specimens along different stress paths. As seen in Fig. 9, the data is somewhat scattering when the axial strain is less than $0.01 \%$ due to the resolution of the LVDT, but we can still clearly see the trend. For each stress path, $E_{\mathrm{sec}}$ decreases continuously as the axial strain increases, indicating the nonlinear soil behavior. Meanwhile, the $E_{\mathrm{sec}}$ value along the axial unloading is highest, the $E_{\mathrm{sec}}$ value along the constant $\mathrm{P}$ unloading is in the middle, and the $E_{\text {sec }}$ value is the lowest along the lateral unloading path. As the strain increases, the difference of the $E_{\text {sec }}$ value decreases. It indicates that the stiffness significantly depends on the stress path, especially at small strains. It should be emphasized that currently the effect of stress path on the small strain stiffness has not been well accounted in the deformation analysis and further researches are needed. These observations in this study are consistent with those in Finno and Kim [12] and Callisto and Rampello [18], in which it was found that $E_{\mathrm{sec}}$ depends on the angle between the load stress path and the consolidation path. Meanwhile, the $E_{\mathrm{sec}}$ values of the specimens at $70 \mathrm{~m}$ are larger than those at $30 \mathrm{~m}$, indicating a stress dependent stiffness as expected. This stress dependent stiffness also should be considered in the deformation analysis.

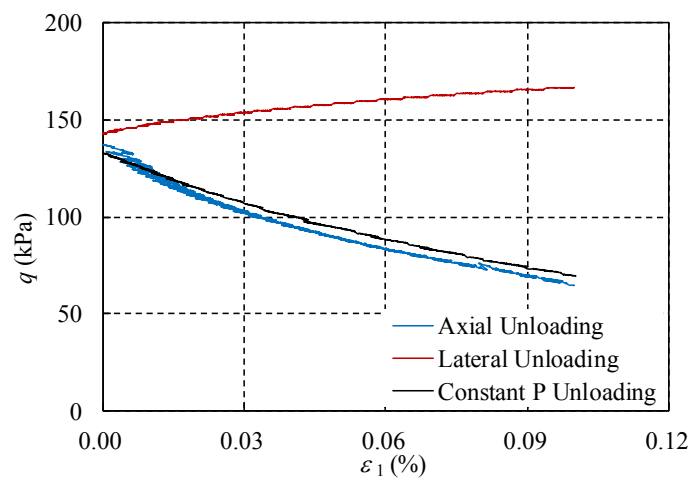

Fig. 8. The stress - strain curve for axial strain $<0.1 \%$

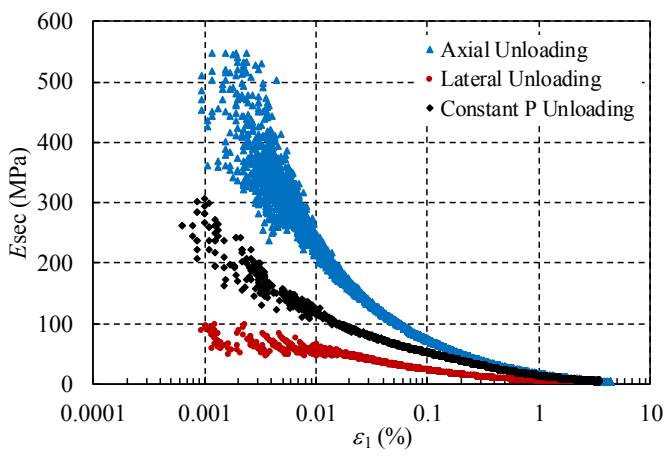

(a) 


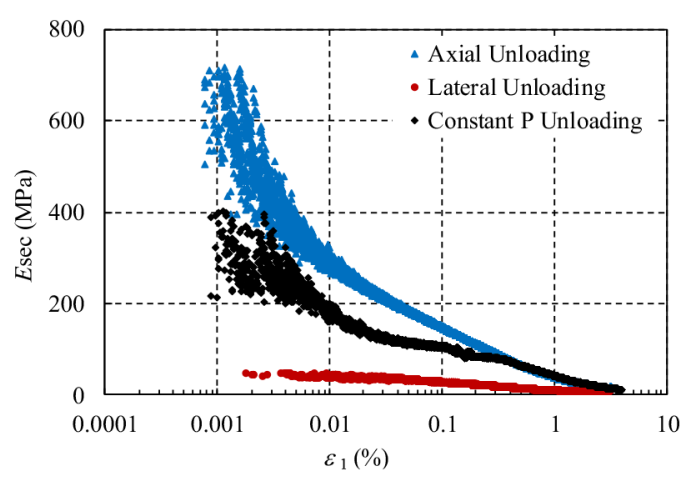

(b)

Fig. 9. The secant Young's modulus $E_{\text {sec }}$ along different stress paths for specimens at depths of (a) $30 \mathrm{~m}$ and (b) $70 \mathrm{~m}$

\section{Conclusions}

In this study, the $K_{0}$ values of the intact Shanghai Clay specimens are determined. It is found that they are in the range of $0.49-0.56$, showing a decrease trend as the density of the specimen increases. Meanwhile, the small strain shear modulus $G_{0 \mathrm{vh}}$ of the specimens during the K0 consolidation is measured by bender element. The $G_{0 \text { vh }}$ values of three specimens for shearing tests along different stress paths are nearly the same and increases as the effective confining pressure increases, indicating the initial stiffness of the specimens are nearly identical. Moreover, the degradation of the secant stiffness with axial strain along different stress path are compared. The results showed that the stiffness significantly depends on the stress path, especially at small strains.

The work presented in this paper is supported by the National Natural Science Foundation of China (Grant nos. 51822809 and 51738010), State Key Laboratory for Geomechanics and Deep Underground Engineering, CUMT (Grant no. SKLGDUEK1712) and the Fundamental Research Funds for the Central Universities. These supports are gratefully acknowledged.

\section{References}

1. J.B. Burland, Can. Geotech. J., 26, 499 (1989)

2. D.G. Anderson, K.H.II. Stokoe, Dynamic Geotechnical Testing (66, STP 654, Philadelphia, 1978)

3. B.O. Hardin, V.P. Drnevich, J. Soil. Mech. Found. Div., 98, 603 (1972)

4. P. De Alba, K. Baldwin, V. Janoo, G. Roe, \& B. Celikkol, Geotech. Test. J., 7, 77 (1984)

5. T. Kokusho, Proceedings of the 8th Asian Regional Conference on Soil Mechanics and Foundation Engineering (215, Vol. 2, Kyoto, 1987)

6. X.Q. Gu, J. Yang, M.S. Huang, Soils Found., 53, 735 (2013)

7. Y.G. Zhou, Y.M. Chen, J. Geotech. Geoenviron., 133, 959 (2007)

8. J.-U. Youn, Y.-W. Choo, D.-S. Kim, Can. Geotech., J. 45, 1426 (2008)
9. J.-S. Lee, J.C. Santamarina, J. Geotech. Geoenviron., 131, 1063 (2005)

10. Q. Li, C. W. W. Ng, G. B. Liu, Can. Geotech. J., 49, 986 (2012)

11. A. Ezaoui, H. Di Benedetto, Geotechnique, 59, 621 (2009)

12. R.J. Finno, T. Kim, J. Geotech. Geoenviron., 138, 526 (2012)

13. X.Q. Gu, J. Hu, M.S. Huang, Granul. Matter, 17, 703 (2015)

14. J. Yang, X.Q. Gu, Geotechnique, 63, 165 (2013)

15. X.Q. Gu, J. Yang, M.S. Huang, G.Y. Gao, Soils Found., 55, 951 (2015)

16. D.W. Hight, A. Gasparre, S. Nishimura, N.A. Minh, R.J. Jardine, M.R.Coop, Geotechnique, 57, 3 (2007)

17. A. Gasparre, S. Nishimura, N.A. Minh, M.R. Coop, R.J. Jardine, Geotechnique, 57, 33 (2007)

18. L. Callisto, S. Rampello, Geotechnique, 52, 547 (2002) 